Research Paper

\title{
Optimization of artificial urine formula for in vitro cellular study compared with native urine
}

\author{
Kanyarat Sueksakit, Visith Thongboonkerd ${ }^{\varpi}$ \\ Medical Proteomics Unit, Office for Research and Development, Faculty of Medicine Siriraj Hospital, Mahidol University, Bangkok 10700, Thailand \\ $\triangle$ Corresponding author: Prof. Visith Thongboonkerd, Head of Medical Proteomics Unit, Office for Research and Development, Siriraj Hospital, Mahidol \\ University, 6 ${ }^{\text {th }}$ Floor - SiMR Building, 2 Wanglang Road, Bangkoknoi, Bangkok 10700, Thailand. Phone: +66-2-4192850; E-mail: thongboonkerd@dr.com (or) \\ vthongbo@yahoo.com \\ (c) The author(s). This is an open access article distributed under the terms of the Creative Commons Attribution License (https://creativecommons.org/licenses/by/4.0/). \\ See http:/ /ivyspring.com/terms for full terms and conditions.
}

Received: 2021.04.16; Accepted: 2021.07.07; Published: 2021.07.23

\begin{abstract}
Several artificial urine $(A U)$ formulas have been developed to mimic the normal urine. Most of them are protein-free, particularly when secreted proteins (secretome) is to be analyzed. However, the normal urine actually contains a tiny amount of proteins. We hypothesized that urinary proteins at physiologic level play a role in preservation of renal cell biology and function. This study evaluated the effects from supplementation of $0-10 \%$ fetal bovine serum (FBS) into the well-established AU-Siriraj protocol on MDCK renal tubular cells. Time to deformation $\left(T_{D}\right)$ was reduced by both native urine and AU-Siriraj without/with FBS compared with complete culture medium (control). Among the native urine and AU-Siriraj without/with FBS, the cells in AU-Siriraj+2.5\% FBS had the longest TD. Supplementation of FBS increased cell death in a dose-dependent manner (but still <10\%). Transepithelial electrical resistance (TER) of the polarized cells in the native urine was comparable to the control, whereas that of the cells in AU-Siriraj+2.5\% FBS had the highest TER. These data indicate that supplementation of $2.5 \%$ FBS into AU-Siriraj can prolong time to deformation and enhance polarization of renal tubular cells. Therefore, $\mathrm{AU}-$ Siriraj-2.5\% FBS is highly recommended for in vitro study of cell biology and function (when secretome is not subjected to analysis).
\end{abstract}

Key words: AU-Siriraj; Cell polarization; Fetal bovine serum; Protein supplement; Renal tubular cell; Transepithelial electrical resistance

\section{Introduction}

Artificial urine (AU) has been developed to mimic the native human urine for various in vitro studies. Several AU formulas have been reported using different kinds of chemicals with various ranges of their concentrations [1]. One of those is our previously established formula, AU-Siriraj, which has been proven as one of the most physiologic AU formulas compared with the other protocols [1]. As such, the AU-Siriraj formula has been widely used in several recent studies for disease mechanisms [2], diagnostics [3], biomarker discovery [4], drug delivery [5-9], crystallization and crystal growth [10], biosensors/bioelectronics [11, 12], etc. Moreover, a recent study has shown that AU-Siriraj can improve the polarization features of renal tubular epithelial cells using a Transwell system [13]. Most of the AU formulas are protein-free to address the effects of treatments, interventions, or experimental inductions on secretory proteins (or secretome) [1]. Note that exogenous proteins can definitely interfere with the analysis and interpretation of changes in the secretion of endogenous proteins [14-16].

The native urine contains mainly water and several various small molecules, including urea, sodium, potassium, chloride, creatinine, phosphate and other compounds $[17,18]$. In addition, the native urine from human and other mammals contains a tiny amount of macromolecules, particularly proteins [19]. One among these urinary proteins is albumin, of which the high level is an important indicator for several kidney diseases, such as diabetic nephropathy, hypertension and chronic kidney 
disease (CKD) $[19,20]$. The normal or physiologic level of urinary albumin is $<30 \mathrm{mg} / 24 \mathrm{~h}$ (or $\mathrm{mg} / \mathrm{g}$ creatinine) (normoalbuminuria). Moderately and severely increased albumin levels are considered when urinary albumin levels are $30-300 \mathrm{mg} / 24 \mathrm{~h}$ (or $\mathrm{mg} / \mathrm{g}$ creatinine) (microalbuminuria) and $>300$ $\mathrm{mg} / 24 \mathrm{~h}$ (or $\mathrm{mg} / \mathrm{g}$ creatinine) (macroalbuminuria), respectively [19]. In addition to albumin, the normal urine contains several other proteins, e.g., immunoglobulins, transferrin, a1-antitrypsin serine proteinase inhibitors, kininogen and bikunin [21, 22]. Normal to mildly increased, moderately increased, and severely increased proteinuria are classified when urinary protein levels are $<150,150-500$, and $>500$ $\mathrm{mg} / 24 \mathrm{~h}$ (or $\mathrm{mg} / \mathrm{g}$ creatinine), respectively [19].

We therefore hypothesized that the normal or physiologic urinary proteins play a role in preservation of renal tubular cell biology and function. In the normal urine, approximately $70 \%$ of urinary proteins are derived from glomerular filtration of the serum/plasma proteins, whereas the rest $(30 \%)$ are from renal tubular secretion (in free forms or as the urinary exosomes or extracellular vesicles) [23-25]. This study thus aimed to evaluate the effects from supplementation of various concentrations of proteins from fetal bovine serum (FBS) into the well-established AU-Siriraj protocol on floating, monolayered and polarized Madin-Darby Canine Kidney (MDCK) renal tubular epithelial cells.

\section{Materials and Methods}

\subsection{Human subjects and urine collection}

All the experiments involving human subjects and clinical samples were reviewed and approved by the Siriraj Institutional Review Board (approval no. Si650/2015). The experiments involving clinical samples were conducted according to the international guidelines, i.e., the Declaration of Helsinki, the Belmont Report, and ICH Good Clinical Practice. Late afternoon midstream urine samples were collected from 12 healthy individuals ( 2 males and 10 females, aged $31.5 \pm 1.18$ years). The urine samples were centrifuged at $300 \times g$ and $4^{\circ} \mathrm{C}$ for $10 \mathrm{~min}$ to eliminate cellular debris. An equal volume of urine samples (10 ml each) from four individuals were randomly combined as one pool to make three different pools for all subsequent experiments.

\subsection{Preparation of AU-Siriraj without or with exogenous protein supplementation}

AU-Siriraj was prepared according to the protocol described previously [1, 13]. The final compositions of this AU were $200 \mathrm{mM}$ urea, $1 \mathrm{mM}$ uric acid, $4 \mathrm{mM}$ creatinine, $5 \mathrm{mM} \mathrm{Na}_{3} \mathrm{C}_{6} \mathrm{H}_{5} \mathrm{O}_{7} \cdot 2 \mathrm{H}_{2} \mathrm{O}, 54$
$\mathrm{mM} \mathrm{NaCl}, 30 \mathrm{mM} \mathrm{KCl}, 15 \mathrm{mM} \mathrm{NH}_{4} \mathrm{Cl}, 3 \mathrm{mM}$ $\mathrm{CaCl}_{2} \cdot 2 \mathrm{H}_{2} \mathrm{O}, 2 \mathrm{mM} \mathrm{MgSO} 4 \cdot 7 \mathrm{H}_{2} \mathrm{O}, 2 \mathrm{mM} \mathrm{NaHCO}, 0.1$ $\mathrm{mM} \mathrm{NaC} \mathrm{O}_{4}, 9 \mathrm{mM} \mathrm{Na} \mathrm{SO}_{4}, 3.6 \mathrm{mM} \mathrm{NaH} \mathrm{PO}_{4} \cdot \mathrm{H}_{2} \mathrm{O}$, and $0.4 \mathrm{mM} \mathrm{Na}_{2} \mathrm{HPO}_{4}$. Final $\mathrm{pH}$, specific gravity, and osmolality of this physiologic AU were 6.2, 1.010 $(\mathrm{g} / \mathrm{ml})$, and $446(\mathrm{mOsm} / \mathrm{kg})$, respectively. To examine the effects of exogenous protein supplementation, $0.625 \%, 1.25 \%, 2.5 \%, 5 \%$ or $10 \%$ fetal bovine serum (FBS) (Gibco, Invitrogen; Grand Island, NY) was added into the AU-Siriraj formula.

\subsection{Cell culture}

MDCK cell line (strain II) (ATCC; Manassas, VA), the most commonly used cell line/strain for in vitro epithelial cell polarity studies [26], was employed. These MDCK cells were maintained in a complete culture medium (containing Eagle's minimum essential medium (MEM) (Gibco) supplemented with $10 \%$ (v/v) heat-inactivated FBS (Gibco), $60 \mathrm{U} / \mathrm{ml}$ penicillin G (Sigma, St. Louis; MO), and $60 \mu \mathrm{g} / \mathrm{ml}$ streptomycin (Sigma)) in a humidified incubator containing $5 \% \mathrm{CO}_{2}$ at $37^{\circ} \mathrm{C}$. The medium was refreshed every day. Floating, monolayered and polarized cells were then prepared for subsequent experiments as follows (see also Figure 1).

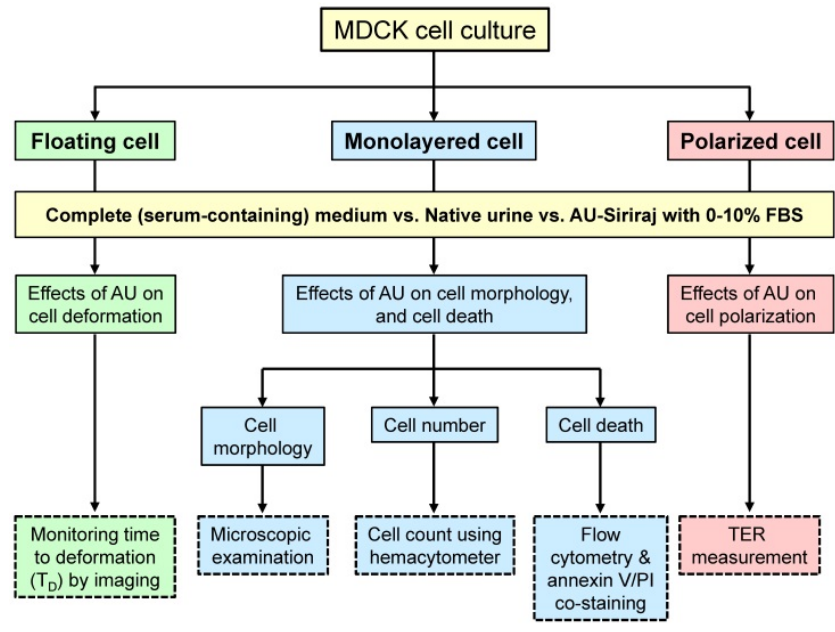

Figure 1: Schematic summary of the study design. Effects of supplementation of fetal bovine serum (FBS) to the artificial urine (AU) on floating, monolayered and polarized MDCK renal tubular epithelial cells were evaluated. Such supplementation was compared with the complete (serum-containing) medium (control) and three different pools of the native urine. Time to deformation ( $T D$ ), cell morphology, cell number, cell death, and transepithelial electrical resistance (TER) were examined.

\subsection{Analysis of time to deformation $\left(T_{D}\right)$ in the floating cells}

The floating cells were used for evaluation of cell tolerance to the AU or native urine. The cells (approximately $7.5 \times 10^{4}$ cells) were seeded in each well of the 24-well plate (Corning Costar; Cambridge, MA) with $1 \mathrm{ml}$ of the complete (serum-containing) culture medium. After incubation in a humidified incubator 
containing $5 \% \mathrm{CO}_{2}$ at $37^{\circ} \mathrm{C}$ for $24 \mathrm{~h}$, the cells were washed with PBS and trypsinized with $0.1 \%$ trypsin in $2.5 \mathrm{mM}$ EDTA/PBS. Thereafter, the cell suspension was centrifuged at $300 \times g$ and $4^{\circ} \mathrm{C}$ for $3 \mathrm{~min}$ and the supernatant containing trypsin was removed. The cells were then resuspended in $1 \mathrm{ml}$ of the complete (serum-containing) medium, native urine, or AU-Siriraj with $0-10 \%$ FBS supplement. Cell morphology was monitored every $10 \mathrm{~min}$ under the Nikon Eclipse Ti-S inverted phase-contrast light microscope (Nikon; Tokyo, Japan). Time to deformation $\left(T_{D}\right)$ was recorded for each sample.

\subsection{Analysis of cell morphology, total number and death in the monolayered cells}

MDCK cells (approximately $1.0 \times 10^{5}$ cells) were seeded in each well of the 6-well plate (Corning Costar) and incubated in complete (serum-containing) medium for $48 \mathrm{~h}$ to allow the monolayer to develop. The cells were incubated in a humidified incubator containing $5 \% \mathrm{CO}_{2}$ at $37^{\circ} \mathrm{C}$ and the medium was refreshed every day. Thereafter, the monolayer was washed with PBS and the cells were further incubated with the complete (serum-containing) medium, native urine, or AU-Siriraj with $0-10 \%$ FBS supplement for 1 h. Cell morphology was imaged using the Nikon Eclipse Ti-S inverted phase-contrast light microscope. The adherent cells were then collected by trypsinization using $0.1 \%$ trypsin in $2.5 \mathrm{mM}$ EDTA/PBS. The total cell number was counted using a hemacytometer.

In parallel, the trypsinized cells were washed with ice-cold PBS. Thereafter, the cell suspension was centrifuged at $500 \times g$ and $4^{\circ} \mathrm{C}$ for $5 \mathrm{~min}$. After PBS removal, the cells were resuspended with annexin $\mathrm{V}$ binding buffer (10 mM HEPES, $140 \mathrm{mM} \mathrm{NaCl}$, and 2.5 $\mathrm{mM} \mathrm{CaCl} 2.2 \mathrm{H}_{2} \mathrm{O}, \mathrm{pH}$ 7.4) (BD Biosciences; San Jose, CA) followed by incubation with FITC-conjugated annexin $\mathrm{V}$ (BD Biosciences) at $25^{\circ} \mathrm{C}$ in the dark for 15 min. Propidium iodide (BD Biosciences) was added and the cell suspension was further incubated for 5 min before analysis by using BD Accuri C6 flow cytometer (BD Biosciences).

\subsection{Measurement of transepithelial electrical resistance (TER) in the polarized cells}

The cells (approximately $7.5 \times 10^{4}$ cells) were seeded on each collagen-coated polyethylene culture insert $\left(1.12-\mathrm{cm}^{2}\right.$ area) of the $12-\mathrm{mm}$ Transwell plate (0.4- $\mu \mathrm{m}$ pore size) (Corning Costar) and grown with the complete (serum-containing) culture medium in both upper and lower chambers of the Transwell. The cells were incubated in a humidified incubator containing $5 \% \mathrm{CO}_{2}$ at $37^{\circ} \mathrm{C}$ and the medium was refreshed every day. After 60 -h incubation, when TER no longer increased and could be stabilized [13], the medium in upper chamber was then replaced with fresh complete (serum-containing) medium, native urine or AU-Siriraj without or with $0.625 \%, 1.25 \%$, $2.5 \%, 5 \%$ or $10 \%$ FBS supplement. After switching culture medium in the upper chamber for $24 \mathrm{~h}$ (or at 84-h post-culture), the polarized MDCK cells were subjected to TER measurement at three different sites in each sample well using Millicell-ERS resistance system (Millipore; Bedford, MA) [27, 28]. The resistance value obtained from the sample well was then subtracted with the background obtained from the blank coated-well without cells filled with the same conditioned medium. TER values were calculated using a following equation.

\section{TER $\left(\mathrm{Ohm} \cdot \mathrm{cm}^{2}\right)$}

$=($ Resistance of sample well - Resistance of blank well) $(\mathrm{Ohm}) \times$ Well area $\left(\mathrm{cm}^{2}\right)$

\subsection{Statistical analysis}

All quantitative data were obtained from three independent experiments and are reported as mean \pm SEM unless stated otherwise. Comparisons among groups of the samples were performed using ANOVA with Tukey's post-hoc test. $P$ values less than 0.05 were considered statistically significant.

\section{Results}

This study examined the effects from supplementation of various concentrations $(0-10 \%)$ of FBS into the well-established AU-Siriraj protocol on floating, monolayered and polarized MDCK renal tubular cells. The cells in a complete culture medium supplemented with 10\% FBS served as the control. The study design is summarized in Figure 1.

To evaluate the cell tolerance to the AU or native urine, the floating MDCK cells were incubated in the complete (serum-containing) medium, native urine, or AU-Siriraj with $0-10 \%$ FBS supplement. Cell morphology was monitored every $10 \mathrm{~min}$ under an inverted phase-contrast light microscope. The data showed that time to deformation $\left(T_{D}\right)$ significantly decreased for all cells exposed to the native urine or AU-Siriraj without/with FBS supplement compared with the control (Figure 2 and Supplementary Figures S1-S10). Comparing among the cells exposed to the native urine or $\mathrm{AU}$, those incubated with AU-Siriraj + 2.5\% FBS had the longest $\mathrm{T}_{\mathrm{D}}$ (Figure 2).

To address the cytotoxic effects, cell morphology, total number and death were examined in the cell monolayers. After the monolayers completely formed, the cells were incubated with the complete (serum-containing) medium, native urine, or AU-Siriraj with $0-10 \%$ FBS supplement for $1 \mathrm{~h}$. 
There were no obvious changes in cell morphology and total number observed in all groups (Figure 3). Flow cytometry using annexin $\mathrm{V} /$ propidium iodide co-staining was performed to evaluate early apoptosis, late apoptosis and necrosis in the cells. Comparing with the control, the cells had slightly greater percentage of total cell death when they were in the native urine, whereas AU-Siriraj without FBS supplement had no significant increase in the cell death (Figure 4). Supplementation of FBS significantly increased cell death in a dose-dependent manner (Figure 4).

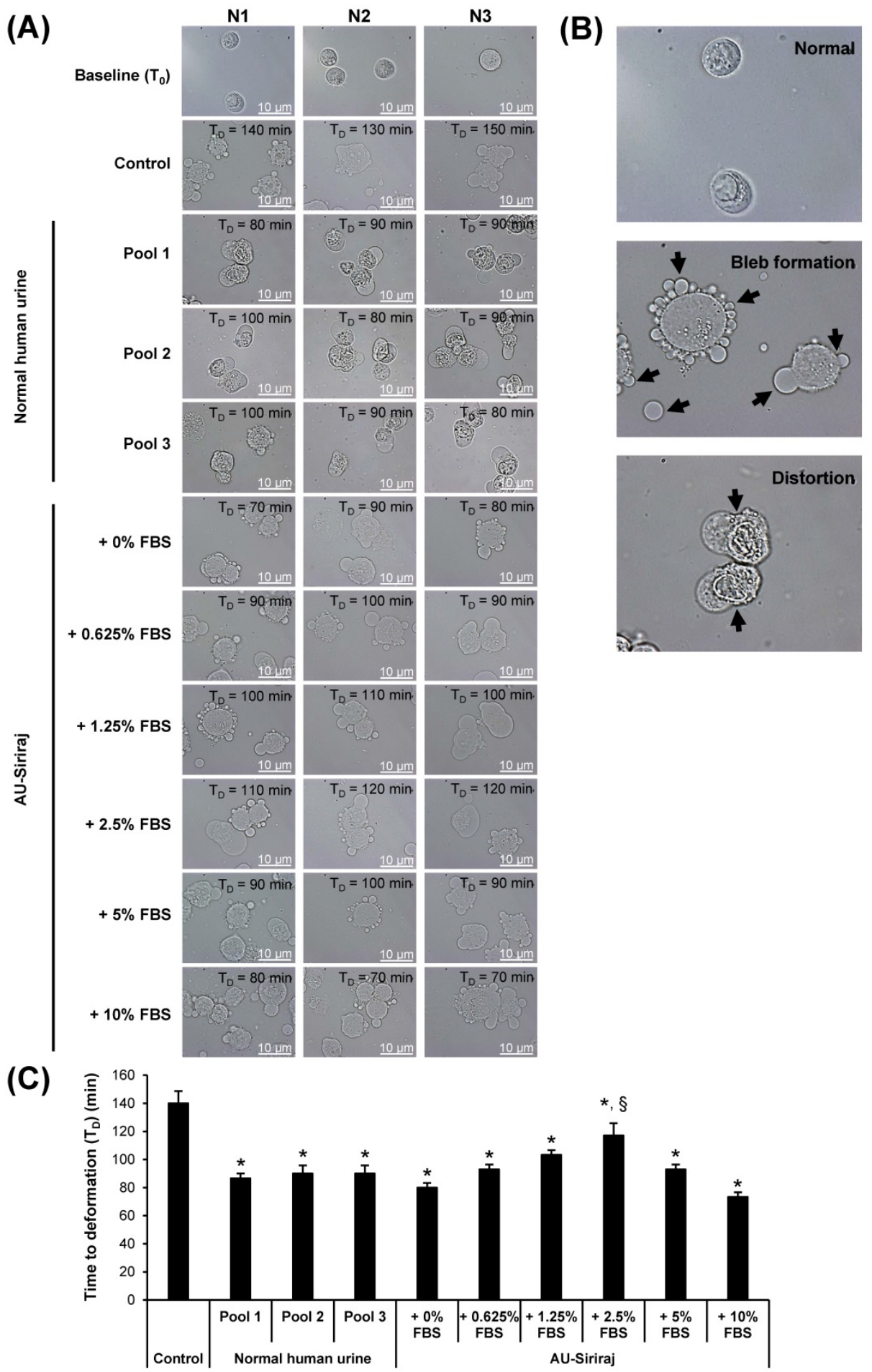

Figure 2: Time to deformation (TD) of floating MDCK cells. (A): The floating cells were incubated with the complete (serum-containing) medium (control), native (normal) human urine, or AU-Siriraj without or with FBS supplement. The cell morphology was monitored every 10 min under an inverted phase-contrast light microscope and the $T_{D}$ was recorded. Original magnification $=1000 \times$ in all panels. Raw data obtained from all replicates of the cells in each group are provided in Supplementary Figures S1-S10. (B): Zoom-in images demonstrating bleb formation and cell distortion as compared with normal morphology of the floating cells. (C): Each bar represents mean \pm SEM of the data obtained from three independent experiments. $*=p<0.05$ shorter than control; $\S=p<0.05$ shorter than native urine and AU-Siriraj supplemented with other concentrations of FBS. 
(A)
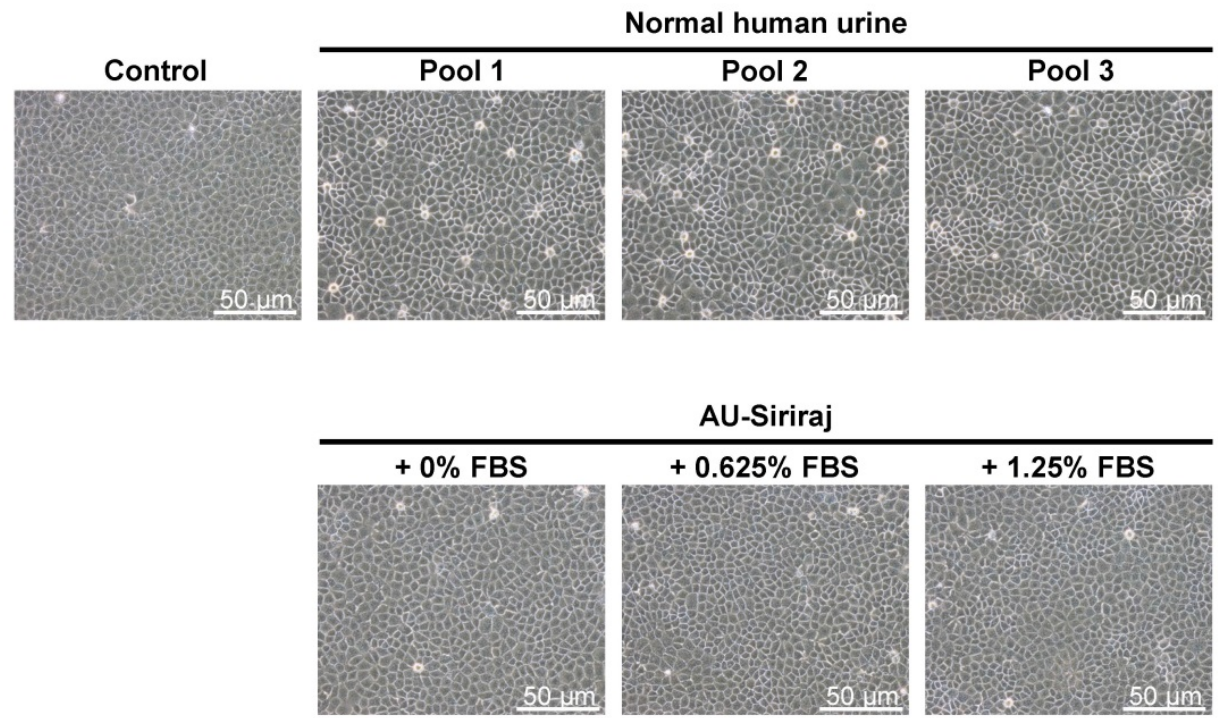

$+2.5 \%$ FBS

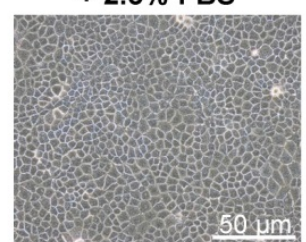

$+5 \%$ FBS

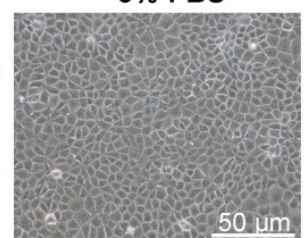

$+10 \%$ FBS

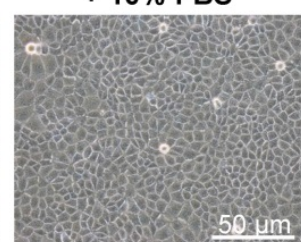

(B)

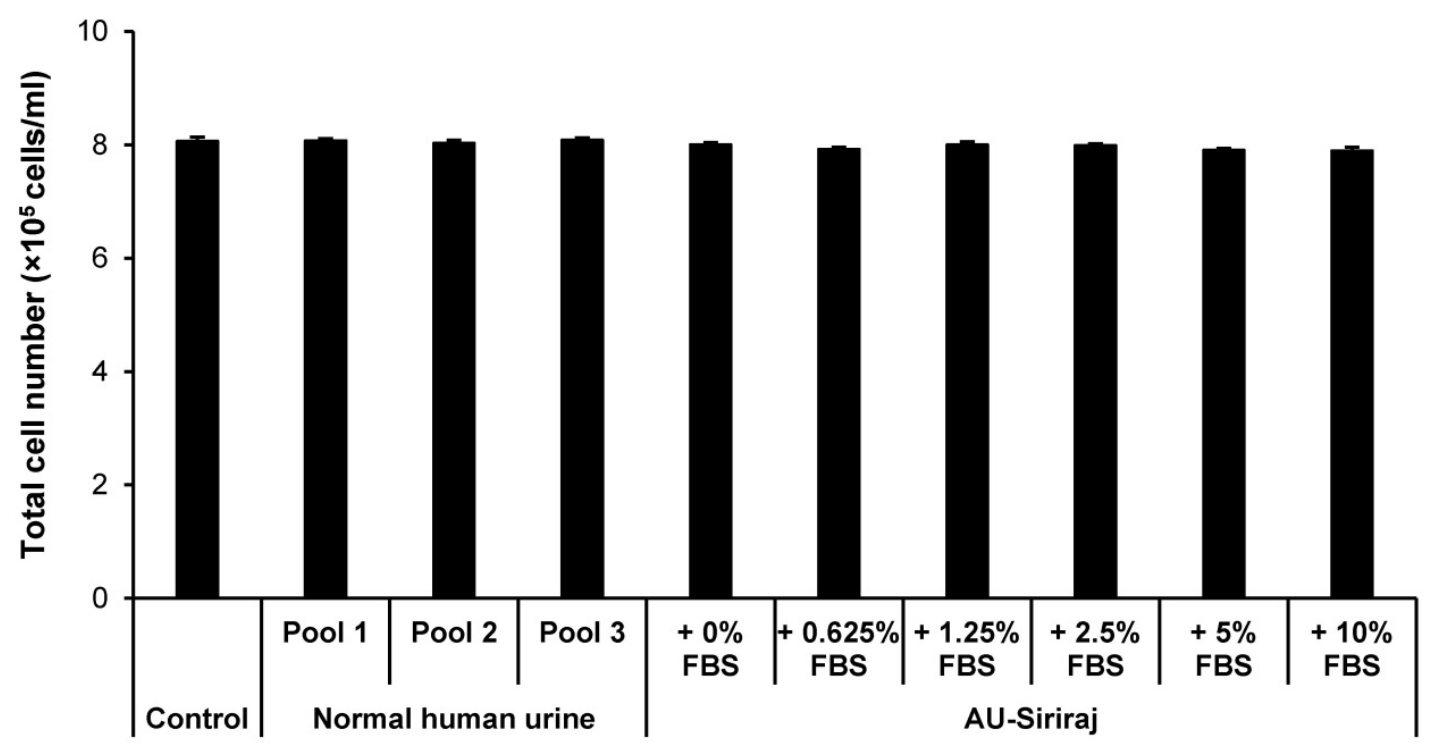

Figure 3: Cell morphology and total number of the monolayered MDCK cells. (A): The cell monolayers were incubated with the complete (serum-containing) medium (control), native (normal) human urine, or AU-Siriraj without or with FBS supplement. After 1-h incubation, the cell morphology was monitored under an inverted phase-contrast light microscope. Original magnification $=200 \times$ in all panels. (B): Total cell number was counted using hemacytometer. Each bar represents mean \pm SEM of the data obtained from three independent experiments. 
(A)

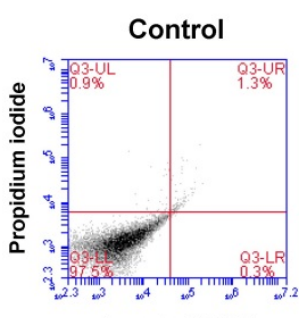

Annexin V-FITC

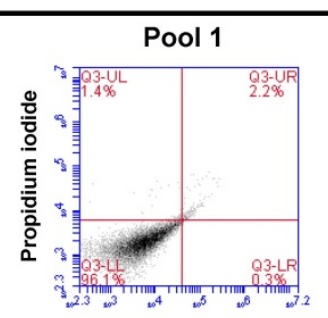

Annexin V-FITC
Normal human urine

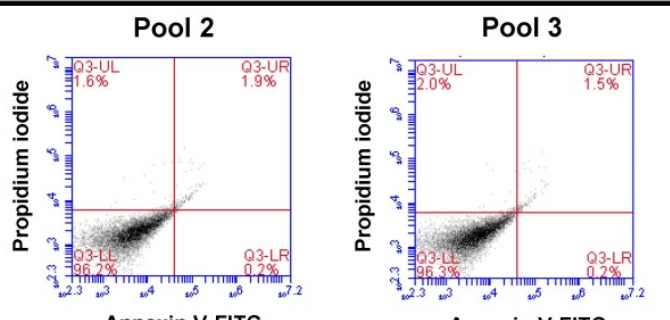

Annexin V-FITC
Annexin V-FITC

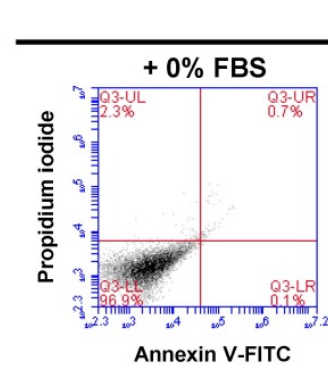

AU-Siriraj

$+0.625 \%$ FBS

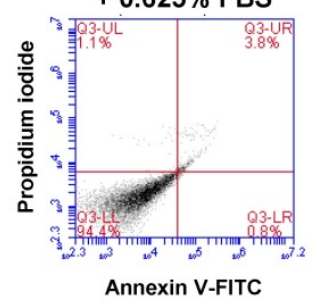

$+1.25 \%$ FBS
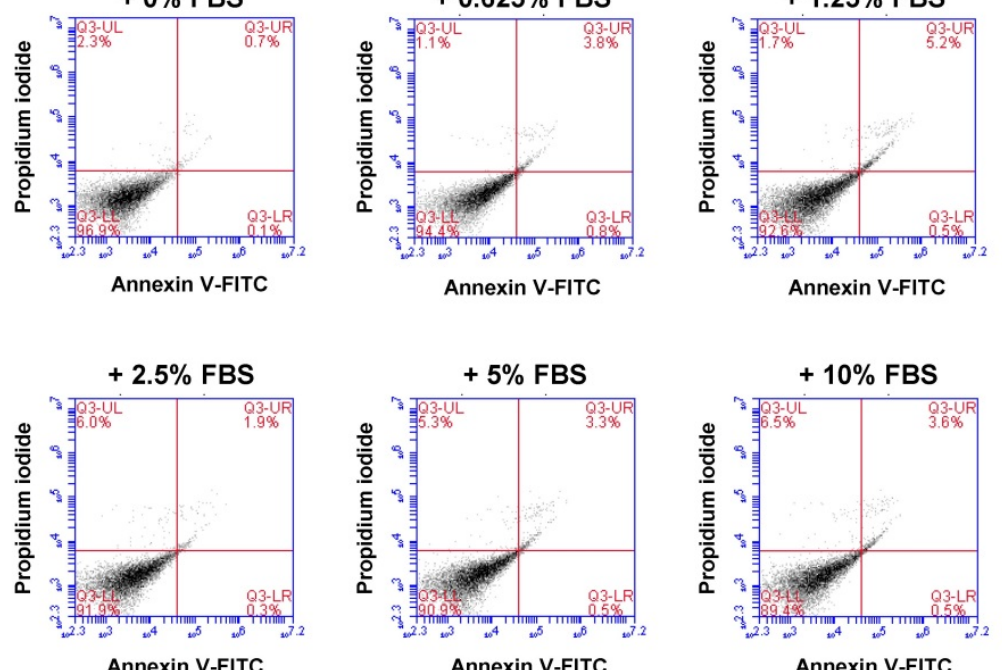

Annexin V-FITC

(B)

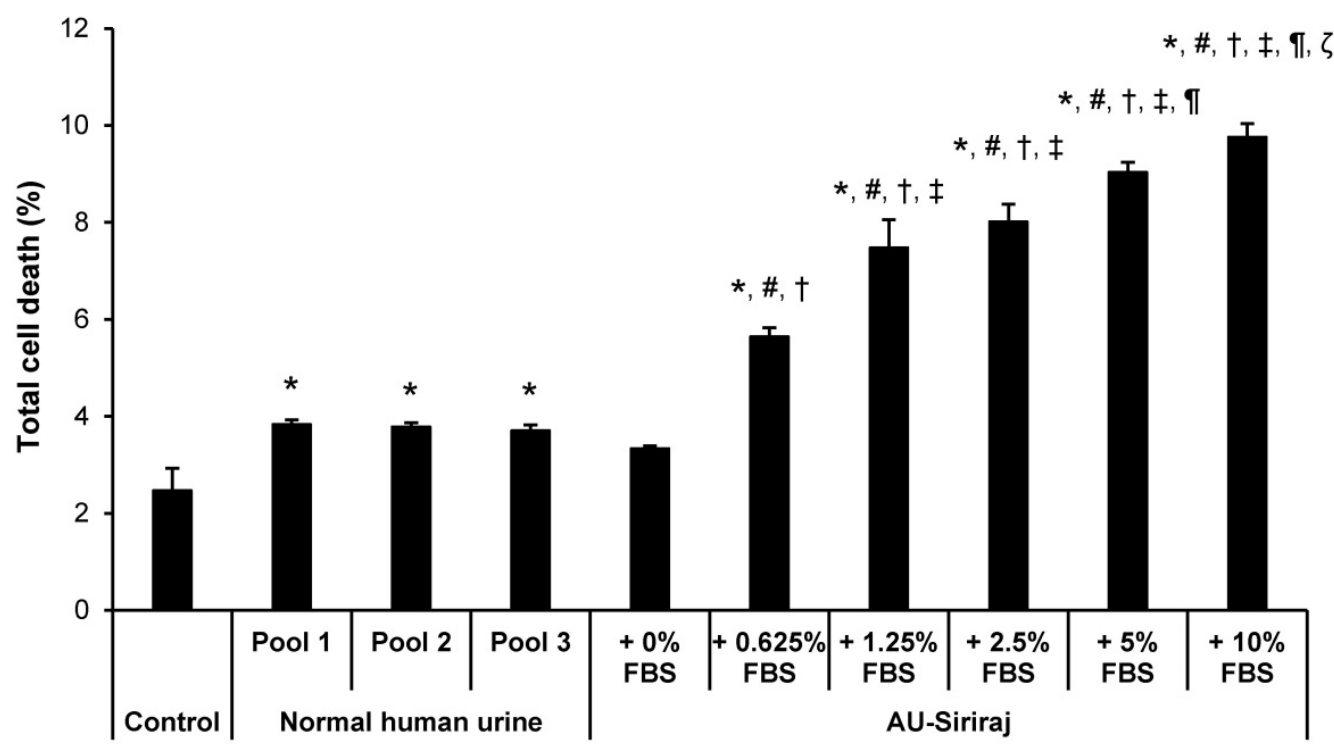

Figure 4: Flow cytometric analysis of cell death in the monolayered MDCK cells. (A): The cell monolayers were incubated with the complete (serum-containing) medium (control), native (normal) human urine, or AU-Siriraj without or with FBS supplement. After l-h incubation, cell death was evaluated and quantified by flow cytometry with annexin V/propidium iodide co-staining. (B): Each bar represents mean \pm SEM of the data obtained from three independent experiments. * $=p<0.05$ greater than control; $\#=p<0.05$ greater than native urine; $\dagger=p<0.05$ greater than AU-Siriraj $+0 \%$ FBS; $\ddagger=p<0.05$ greater than AU-Siriraj $+0.625 \%$ FBS; $\mathbb{T}=p<0.05$ greater than AU-Siriraj + $2.5 \% \mathrm{FBS} ; \zeta=p<0.05$ greater than AU-Siriraj $+5 \%$ FBS. 
To analyze the cell integrity and polarization, TER was measured. After 60-h incubation, when TER was stabilized, the medium in upper chamber of each well of the Transwell plate was replaced with fresh complete (serum-containing) medium, native urine or AU-Siriraj without or with $0.625 \%, 1.25 \%, 2.5 \%, 5 \%$ or $10 \%$ FBS supplement. After switching culture medium in the upper chamber for $24 \mathrm{~h}$ (or at 84-h post-culture), TER was measured. The data showed that TER of the cells in the native urine was comparable to the control (Figure 5). Comparing with the control and native urine, all AU-Siriraj formulas without or with FBS supplement significantly increased the TER in the polarized cells. Among these, the cells incubated with AU-Siriraj + 2.5\% FBS in the upper chamber of the Transwell had the highest TER, indicating that their fence function and polarization were most complete (Figure 5).

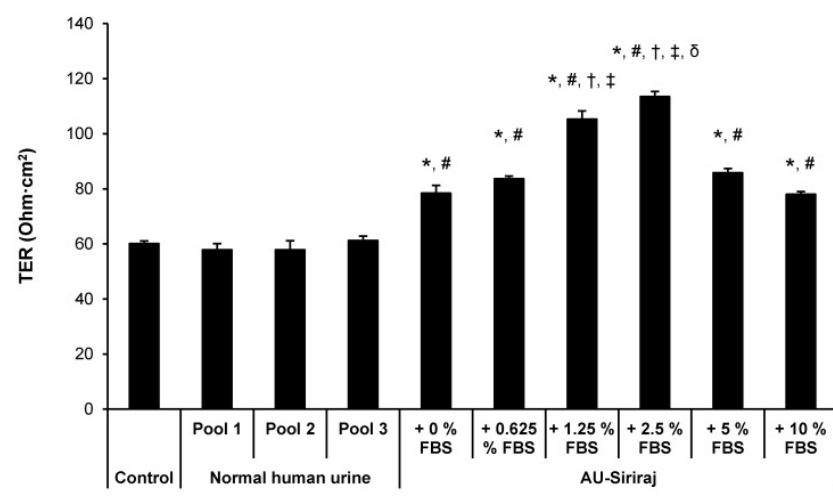

Figure 5: Transepithelial electrical resistance (TER) of the polarized MDCK cells. Polarization of the MDCK cells was induced using a Transwell system. After 60-h incubation with complete (serum-containing) medium, when TER was stabilized, the medium in the upper chamber was replaced with fresh complete (serum-containing) medium, native urine or AU-Siriraj without or with FBS supplement. After switching culture medium in the upper chamber for $24 \mathrm{~h}$ (or at 84-h post-culture), TER was measured. Each bar represents mean \pm SEM of the data obtained from three independent experiments. $*=p<0.05$ greater than control; \# = $p<0.05$ greater than native urine; $\dagger=p<0.05$ greater than AU-Siriraj $+0 \%$ FBS; $\ddagger=$ $p<0.05$ greater than AU-Siriraj + 0.625\% FBS; $\delta=p<0.05$ greater than AU-Siriraj + $1.25 \% \mathrm{FBS}$

\section{Discussion}

The present study addressed whether supplementation of exogenous proteins from FBS could enhance cell biology and function in vitro. The AU formula used for such investigations was AU-Siriraj, which has been documented as one of the most physiologic AU formulas available to date [1]. This physiologic AU formula has been widely used in several recent biomedical studies [2-12]. It is suitable for secretome analysis and the study that avoids contaminations of exogenous proteins (i.e., evaluation of secretory endogenous cytokines/chemokines) [14-16]. However, renal tubular cells are surrounded by the blood from capillary mesh at basolateral site, whereas their apical membranes are exposed to renal tubular fluid, which contains several various proteins filtrated from the plasma and secreted from the upstream cells [23-25]. Therefore, it would be logical to formulate the most physiologic AU to simulate the native urine by supplementation of minimal amount of plasma/serum proteins.

For the native urine, diurnal variations are the important factors determining the urinary compositions [29, 30]. The first or second morning urine is suitable for measurement of urinary protein concentration [29, 30]. However, the first or second morning urine is not suitable for our present study because it can be associated with cytotoxicity [31,32]. In addition, 24-h urine is commonly used for precise measurement of urinary albumin/protein excretion as recommended by the Kidney Disease: Improving Global Outcomes (KDIGO) Clinical Practice Guideline [19]. Nevertheless, the 24-h urine may have bacterial overgrowth and preservatives are usually added into the collecting container [33]. By contrast, the recent data have shown that late afternoon urine is more appropriate and serves as the sample of choice for healthy children [34]. In addition, the random afternoon urine from adults has been used for urinary proteome analysis and biomarker discovery [35-37]. Moreover, early or late afternoon urine is more accurate to reflect 24-h urine osmolality and specific gravity as compared with morning, evening or overnight urine $[36,37]$. Along with practical points and recommendations for urinary proteome analysis by The Human Kidney and Urine Proteome Project (HKUPP) [29, 30], our study therefore used late afternoon midstream void to prevent the aforementioned confounding factors. Note that there were no significant differences of the effects from different native urine pools observed in all assays in this study (each of the three pools were collected from different groups of four individuals).

To screen for the optimal concentration of FBS that should be added into the AU-Siriraj formula, time to deformation $\left(T_{D}\right)$ of the floating MDCK cells was first evaluated. The $T_{D}$ is one of the indicators for cell tolerance during treatment conditions [38, 39]. The cell deformation can be determined when there is (are) cell shape change, shrinkage, membrane bleb formation, spiking, distortion, etc. [38, 39]. It was not unexpected that both the native urine and $A U$ formulas caused significant decrease in $T_{D}$. In other words, the cells were less tolerant when they were exposed to native urine or AU compared with the complete (serum-containing) medium. Interestingly, supplementation of $2.5 \%$ FBS into the AU-Siriraj formula provided the longest $\mathrm{T}_{\mathrm{D}}$ as compared with the other FBS concentrations. It's likely the optimal 
concentration of FBS that is compatible with the cell biology. Such improved tolerance might be the effect from proteins, osmolality, $\mathrm{pH}$, chemicals, ions, or trace elements in the serum.

Exposure to an excess amount of urinary proteins (as in the case of macroalbuminuria or overt proteinuria) can induce cytotoxicity [40-42]. Flow cytometry using annexin $\mathrm{V} /$ propidium iodide showed a slight increase in cell death by the native urine. This was not unexpected because the native urine contains proteins and also metabolites as well as waste products that might be responsible for such cytotoxic effects [40-42]. This data was consistent with the $T_{D}$ as aforementioned. It has been evidenced that cell deformability is associated with cytotoxicity and cell death, and the late stage of cell deformation can lead to a loss of the cell membrane and ultimately cellular disruption and death [43,44]. On the other hand, the protein-free AU-Siriraj formula did not induce the cell death, consistent with our previous study demonstrating that this AU formula is quite physiologic [1]. However, supplementation of FBS significantly increased the cell death in a dose-dependent manner. Note that the total cell death remained $<10 \%$ for all conditions. In concordance, studies on different cell types have shown that the culture medium containing 10\% FBS and 50\% AU (using the protocol established by Griffith et al. [45]) reduced cell viability and induced cytotoxicity in UROtsa cells after incubation for $24 \mathrm{~h}$ [46]. Likewise, the prolonged incubation (for 7 days) with 10\% FBS and $30 \%$ AU also induced the cytotoxicity [46]. Again, the excess amount of proteins in the urine might be responsible for such cytotoxicity, consistent with the data reported previously for macroalbuminuria and overt proteinuria [40-42]. It should be noted that FBS was derived from bovine, whereas MDCK cells were originated from canine. Difference in species may or may not generate a cross-reactivity. However, this effect (if any) is subtle as routine cell culture also uses FBS for MDCK cells without any problem of the cross-reactivity recognized.

Tight junction is important for the formation of apical intercellular junctional complex that governs fence function of the polarized cells. This junctional complex also plays roles in epithelial cell proliferation and differentiation [47, 48]. Our present study measured TER, which represents the integrity of the tight junction and serves as an indicator of the fence function of the polarized cells. In concordance with our previous study [13], the AU-Siriraj without FBS supplement significantly increased the TER, indicating the more complete polarization as compared with the conventional polarized cell culture using complete medium for both upper and lower chambers. For the in vivo milieu, the apical membranes of renal tubular epithelial cells are exposed to renal tubular fluid (represented by AU in the upper chamber of the Transwell). On the other side, the basolateral membranes of renal tubular cells are exposed to blood and nutrients from capillary mesh (represented by the complete (serum-containing) medium in the lower chamber of the Transwell). Therefore, it was not surprising that using AU in the upper chamber could enhance the cell polarization [13]. Finally, our data also demonstrated that supplementation of $2.5 \%$ FBS into the AU-Siriraj formula could enhance the TER to its highest level. These data indicate that $2.5 \%$ is the optimal concentration of FBS that is suitable for supplementation into the AU-Siriraj formula for cell biology and functional studies.

In summary, our findings indicate that AU-Siriraj supplemented with 2.5\% FBS is superior to the native urine and AU-Siriraj without FBS supplementation in terms of the cell tolerance (determined by $\mathrm{T}_{\mathrm{D}}$ ) and cell polarization (determined by TER). Higher concentrations of the supplemental FBS do not improve the cell tolerance and polarization, and on the other hand, induce greater cell death. Therefore, supplementation of $2.5 \%$ FBS into the AU-Siriraj formula is highly recommended for the in vitro study of cell biology and physiology. However, the protein-free AU-Siriraj is still useful, particularly for secretome analysis and the study of secretory endogenous proteins that cannot compromise the interference from exogenous proteins.

\section{Supplementary Material}

Supplementary figures.

http://www.medsci.org/v18p3271s1.pdf

\section{Acknowledgements}

This study was supported by The Office of National Higher Education Science Research and Innovation Policy Council (NXPO) through PMU-B and the Thailand Research Fund (IRN60W0004). VT is supported by "Chalermphrakiat" and "Research Staff" Grants from Faculty of Medicine Siriraj Hospital.

\section{Author Contributions}

KS and VT designed research; KS performed experiments; KS and VT analyzed data; KS and VT wrote the manuscript; All authors reviewed and approved the manuscript.

\section{Competing Interests}

The authors have declared that no competing 


\section{interest exists.}

\section{References}

1. Chutipongtanate S, Thongboonkerd V. Systematic comparisons of artificial urine formulas for in vitro cellular study. Anal Biochem. 2010; 402: 110-2.

2. Ma J, Cai X, Bao Y, Yao H, Li G. Uropathogenic Escherichia coli preferentially utilize metabolites in urine for nucleotide biosynthesis through salvage pathways. Int J Med Microbiol. 2018; 308: 990-9.

3. Reyes S, Le N, Fuentes MD, Upegui J, Dikici E, Broyles D, et al. An Intact Cell Bioluminescence-Based Assay for the Simple and Rapid Diagnosis of Urinary Tract Infection. Int J Mol Sci. 2020; 21: 5015.

4. Sun Y, Xie L, Feng F, Han Q, Wei L, Tang Z, et al. Simultaneous analysis of two urinary biomarkers of oxidative damage to DNA and RNA based on packed-fiber solid phase extraction coupled with high-performance liquid chromatography. J Chromatogr B Analyt Technol Biomed Life Sci. 2020; 1159: 122358.

5. Wang B, Zhang $\mathrm{K}$, Wang J, Zhao R, Zhang Q, Kong X. Poly(amidoamine)-modified mesoporous silica nanoparticles as a mucoadhesive drug delivery system for potential bladder cancer therapy. Colloids Surf B Biointerfaces. 2020; 189: 110832

6. Brauner B, Schwarz P, Wirth M, Gabor F. Micro vs. nano: PLGA particles loaded with trimethoprim for instillative treatment of urinary tract infections. Int J Pharm. 2020; 579: 119158.

7. Kolawole OM, Lau WM, Khutoryanskiy VV. Chitosan/beta-glycerophosphate in situ gelling mucoadhesive systems for intravesical delivery of mitomycin-C. Int J Pharm X. 2019; 1: 100007.

8. Kaldybekov DB, Filippov SK, Radulescu A, Khutoryanskiy VV. Maleimide-functionalised PLGA-PEG nanoparticles as mucoadhesive carriers for intravesical drug delivery. Eur J Pharm Biopharm. 2019; 143: 24-34.

9. Kolawole OM, Lau WM, Khutoryanskiy VV. Synthesis and Evaluation of Boronated Chitosan as a Mucoadhesive Polymer for Intravesical Drug Delivery. J Pharm Sci. 2019; 108: 3046-53.

10. Boadi EA, Deems NJ, Raub CB, Bandyopadhyay BC. Matting Calcium Crystals by Melamine Improves Stabilization and Prevents Dissolution. Cryst Growth Des. 2019; 19: 6636-48.

11. Gan Y, Hu N, He C, Zhou S, Tu J, Liang T, et al. MnO2 nanosheets as the biomimetic oxidase for rapid and sensitive oxalate detection combining with bionic E-eye. Biosens Bioelectron. 2019; 130: 254-61.

12. Income K, Ratnarathorn N, Khamchaiyo N, Srisuvo C, Ruckthong L, Dungchai W. Disposable Nonenzymatic Uric Acid and Creatinine Sensors Using muPAD Coupled with Screen-Printed Reduced Graphene Oxide-Gold Nanocomposites. Int J Anal Chem. 2019; 2019: 3457247.

13. Vinaiphat A, Charngkaew K, Thongboonkerd V. More complete polarization of renal tubular epithelial cells by artificial urine. Cell Death Discov. 2018; 5: 47.

14. Matafora V, Bachi A. Secret3D Workflow for Secretome Analysis. STAR Protoc. 2020; 1: 100162

15. Uhlen M, Karlsson MJ, Hober A, Svensson AS, Scheffel J, Kotol D, et al. The human secretome. Sci Signal. 2019; 12: eaaz0274.

16. Kanlaya R, Thongboonkerd V. Quantitative peptidomics of endogenous peptides involved in TGF-beta1-induced epithelial mesenchymal transition of renal epithelial cells. Cell Death Discov. 2018; 4: 9.

17. Bouatra S, Aziat F, Mandal R, Guo AC, Wilson MR, Knox C, et al. The human urine metabolome PLoS One 2013; 8: e73076.

18. Zhu W, Mai Z, Qin J, Duan X, Liu Y, Zhao Z, et al. Difference in 24-Hour Urine Composition between Diabetic and Non-Diabetic Adults without Nephrolithiasis. PLoS One. 2016; 11: e0150006.

19. Kidney Disease: Improving Global Outcomes Diabetes Work G. KDIGO 2020 Clinical Practice Guideline for Diabetes Management in Chronic Kidney Disease. Kidney Int. 2020; 98: S1-S115.

20. Giglio RV, Lo Sasso B, Agnello L, Bivona G, Maniscalco R, Ligi D, et al. Recent Updates and Advances in the Use of Glycated Albumin for the Diagnosis and Monitoring of Diabetes and Renal, Cerebro- and Cardio-Metabolic Diseases. J Clin Med. 2020; 9: 3634.

21. Thongboonkerd V, McLeish KR, Arthur JM, Klein JB. Proteomic analysis of normal human urinary proteins isolated by acetone precipitation or ultracentrifugation. Kidney Int. 2002; 62: 1461-9.

22. Thongboonkerd V, Klein JB, Arthur JM. Proteomic identification of a large complement of rat urinary proteins. Nephron Exp Nephrol. 2003; 95: e69-e78.

23. Thongboonkerd V. Roles for Exosome in Various Kidney Diseases and Disorders. Front Pharmacol. 2019; 10: 1655.

24. Thongboonkerd V. Current status of renal and urinary proteomics: ready for routine clinical application? Nephrol Dial Transplant. 2010; 25: 11-6.

25. Thongboonkerd V. Urinary proteomics: towards biomarker discovery, diagnostics and prognostics. Mol Biosyst. 2008; 4: 810-5.

26. Dukes JD, Whitley $\mathrm{P}$, Chalmers $\mathrm{AD}$. The MDCK variety pack: choosing the right strain. BMC Cell Biol. 2011; 12: 43.

27. Peerapen P, Thongboonkerd V. p38 MAPK mediates calcium oxalate crystal-induced tight junction disruption in distal renal tubular epithelial cells. Sci Rep. 2013; 3: 1041.

28. Peerapen P, Thongboonkerd V. Effects of calcium oxalate monohydrate crystals on expression and function of tight junction of renal tubular epithelial cells. Lab Invest. 2011; 91: 97-105.
29. Yamamoto T, Langham RG, Ronco P, Knepper MA, Thongboonkerd V. Towards standard protocols and guidelines for urine proteomics: A report on the Human Kidney and Urine Proteome Project (HKUPP) Symposium and Workshop 6 October 2007, Seoul, Korea and 1 November 2007, San Francisco, CA, USA. Proteomics. 2008; 8: 2156-9.

30. Thongboonkerd V. Practical points in urinary proteomics. J Proteome Res. 2007; 6: 3881-90.

31. Brisuda A, Pazourkova E, Soukup V, Horinek A, Hrbacek J, Capoun O, et al. Urinary Cell-Free DNA Quantification as Non-Invasive Biomarker in Patients with Bladder Cancer. Urol Int. 2016; 96: 25-31.

32. Streleckiene G, Reid HM, Arnold N, Bauerschlag D, Forster M. Quantifying cell free DNA in urine: comparison between commercial kits, impact of gender and inter-individual variation. Biotechniques. 2018; 64: 225-30.

33. Thongboonkerd V, Saetun P. Bacterial Overgrowth Affects Urinary Proteome Analysis: Recommendation for Centrifugation, Temperature, Duration, and the Use of Preservatives during Sample Collection. J Proteome Res. 2007; 6: 4173-81.

34. Suh H, Summers LG, Seal AD, Colburn AT, Mauromoustakos A, Perrier ET, et al. Afternoon urine osmolality is equivalent to $24 \mathrm{~h}$ for hydration assessment in healthy children. Eur J Clin Nutr. 2020; 74: 884-90.

35. Thongboonkerd V, Mungdee S, Chiangjong W. Should urine $\mathrm{pH}$ be adjusted prior to gel-based proteome analysis? J Proteome Res. 2009; 8: 3206-11.

36. Bottin JH, Lemetais G, Poupin M, Jimenez L, Perrier ET. Equivalence of afternoon spot and 24-h urinary hydration biomarkers in free-living healthy adults. Eur J Clin Nutr. 2016; 70: 904-7.

37. Perrier E, Demazieres A, Girard N, Pross N, Osbild D, Metzger D, et al. Circadian variation and responsiveness of hydration biomarkers to changes in daily water intake. Eur J Appl Physiol. 2013; 113: 2143-51.

38. Pravincumar P, Bader DL, Knight MM. Viscoelastic cell mechanics and actin remodelling are dependent on the rate of applied pressure. PLoS One. 2012; 7: e43938.

39. Harris AR, Peter L, Bellis J, Baum B, Kabla AJ, Charras GT. Characterizing the mechanics of cultured cell monolayers. Proc Natl Acad Sci U S A. 2012; 109: 16449-54.

40. Li X, Zou T, Wang S, Wu H, Wu M, Liu Z, et al. Mechanism and restoration strategy of lysosomal abnormalities induced by urinary protein overload in proximal tubule epithelial cells. Dev Dyn. 2021; 250: 943-54.

41. Izzedine H, Soria JC, Escudier B. Proteinuria and VEGF-targeted therapies: an underestimated toxicity? J Nephrol. 2013; 26: 807-10.

42. Baines RJ, Brunskill NJ. Tubular toxicity of proteinuria. Nat Rev Nephrol. 2011; 7: 177-80.

43. Wang X, Liu H, Zhu M, Cao C, Xu Z, Tsatskis Y, et al. Mechanical stability of the cell nucleus - roles played by the cytoskeleton in nuclear deformation and strain recovery. J Cell Sci. 2018; 131: jcs209627.

44. Valon L, Levayer R. Dying under pressure: cellular characterisation and in vivo functions of cell death induced by compaction. Biol Cell. 2019; 111: 51-66.

45. Griffith DP, Musher DM, Itin C. Urease. The primary cause of infection-induced urinary stones. Invest Urol. 1976; 13: 346-50.

46. Arndt P, Leistner ND, Neuss S, Kaltbeitzel D, Brook GA, Grosse J. Artificial urine and FBS supplemented media in cytocompatibility assays for PLGA-PEG-based intravesical devices using the urothelium cell line UROtsa. J Biomed Mater Res B Appl Biomater. 2018; 106: 2140-7.

47. Zihni C, Mills C, Matter K, Balda MS. Tight junctions: from simple barriers to multifunctional molecular gates. Nat Rev Mol Cell Biol. 2016; 17: 564-80.

48. Bhat AA, Uppada S, Achkar IW, Hashem S, Yadav SK, Shanmugakonar M, et al. Tight Junction Proteins and Signaling Pathways in Cancer and Inflammation: A Functional Crosstalk. Front Physiol. 2018; 9: 1942. 